\title{
Evaluation of effectiveness of kinesiotaping in supporting of rehabilitation of patients after meniscus injury. Preliminary report
}

\author{
Dariusz Boguszewski', Iwona Tomaszewska², Jakub Grzegorz Adamczyk' ${ }^{1,3}$, Dariusz Białoszewski' \\ ${ }^{1}$ Department of Rehabilitation, Physiotherapy Division. Medical University of Warsaw, Poland, ${ }^{2}$ Rehabilitation Center in Western Hospital in \\ Grodzisk Mazowiecki, Poland, ${ }^{3}$ Institute of Theory of Sport. Academy of Physical Education of Jozef Pilsudski in Warsaw, Poland
}

\section{A B S T R A C T}

Objective: Kinesiotaping (KT) is a method being increasingly more often applied in rehabilitation of movement system. The aim of the study was to assess the effect of kinesiotaping on the rehabilitation result in patients with damaged meniscus. Material and Methods: The study enrolled 23 patients ( 14 women and 9 men) aged between 20 to 41 years. The patients were at random divided into two groups: Group 1 (the experimental group) which received kinesiotaping application, and Group 2 (the control group), which had similar rehabilitation protocol except for the KT application. Results: All participants demonstrated a significant improvement in the range of knee flexion and extension of the injured limb as soon as the end of the first week of the rehabilitation $(p<0.001)$. This tendency persisted in the following weeks until $28^{\text {th }}$ day. Significant swelling reduction was found at patients from the experimental group in all consecutive measurements. The greatest difference $(p<0.001)$ was noted at the beginning of the rehabilitation. After 28 days of rehabilitation, pain intensity and frequency had significantly decreased at all patients $(p<0.001)$. Patients from the control group used analgesics significantly more often. Conclusions: The used KT application contributed to a faster improvement of the range of joint motion and reduction of oedema. A similar reduction in pain intensity was observed at all research participants. However, pain considerably less often forced patients from the experimental group to use analgesics.

Key Words: Kinesiotaping, rehabilitation, joint motion, oedema.
Access this article online Website:

http://nepjol.info/index.php/AJMS

DOI: $10.3126 / a j m s . v 6 i 4.11809$

\section{INTRODUCTION}

Nowadays more and more people are practicing recreational forms of movement such as: Alpine skiing, snowboarding, jogging, volleyball, football or tennis. The active lifestyle, especially advisable from the point of view of prophylaxis of civilization diseases - particularly of illnesses of circulatory system, can have influence on more and more frequent traumatic damages of the knee joint. ${ }^{1-4}$ Injuries of this joint most often refer to sacral ligaments and menisci. ${ }^{5}$

Traumata of the knee joint occur usually at persons doing sport recreationally and professionally. As a result of direct contact with the opponent or with the ground e.g. hit, hit and fall or kick. It is an immediate mechanism. Instead, the indirect trauma can be a consequence of the torsional motion or the combination of motions exceeding physiological range of movement. It is sometimes a result of the traffic accident or fall from the height..$^{6-8}$

In the correct functioning of the knee joint, menisci play the essential role. They do not work in the isolation, and their contribution to the dynamic stabilization has not been completely learnt, nonetheless it cannot be omitted. Therefore, menisci resection is limited if possible. The joint completely devoid of meniscus may work long and well, though, there can appear the premature wear syndrome, consequential to the absence of sufficient protection of articular cartilage. The objective of rehabilitation after 
arthroscopic treatments is elimination of pain complaints, discomfort, recovery of the entire joint function, and also prevention of repeated injuries. ${ }^{9,10}$

Treatment of traumata of the knee joint causes many problems. This refers to the diagnosis, method of treatment, rehabilitation as well as making a decision about the possibility of returning to the physical activity. ${ }^{10,11}$

The main cognitive objective of the research was the evaluation of effectiveness of kinesiotaping as an adjunct to rehabilitation of persons with injured anterior sacral ligament.

\section{MATERIAL AND METHODS}

The study enrolled 23 patients, women $(\mathrm{n}=14)$ and men $(n=9)$ aged between 20 to 41 years (average 30.9 years of age). The patients were randomly divided into two groups: Group 1 - the experimental group $(\mathrm{n}=11)$ which received kinesiotaping application, and Group 2 - the control group $(\mathrm{n}=12)$, which had similar rehabilitation procedure except for the KT application. The research was done on ambulatory patients in the John Paul II Western Hospital in Grodzisk Mazowiecki. All patients from the Group 1 have been receiving similar application for four weeks. Tapes were changed every seventh day, then the circumferential and goniometrical measurement were taken.

All measurements were made four times every seventh day. Each time three measurements were taken, rejecting extreme outcomes. The range of motion in the joint was measured by means of goniometer. The examination was performed on both limbs for comparative reasons. During the measurement of the range of flexion, the patient laid front, with the foot of the examined limb off the couch. The pelvis and thigh were stabilized by means of slings. The axis of goniometer was placed near the heads of the fibulae. The shoulder was motionless, placed along the longitudinal axis of the thigh, directed on the greater trochanter of the femur, while the moving shoulder was positioned along the tibia, aimed at the lateral ankle. The person being tested performed flexion, and the moving shoulder of the goniometer shifted together with the tibia. At the end of motion, the result was read. The measurement of extension was as follows-the patient was in the position of the front lying, the limb being examined was off the couch, so that the knee joint was not supported, therefore it made possible the examination of the probable hyperextension. The stabilization of the pelvis and thigh: the motionless shoulder lying along the longitudinal axis of the thigh, directed on the greater trochanter of the femur, while the moving shoulder along the tibia, was aimed at the lateral ankle. Circumference of limbs (in three places) was also measured with a centimetre tape. Measurement was performed on both limbs for the comparative reasons, without the tape stretching, with accuracy up to $0.5 \mathrm{~cm}$. The first measurement was femoral 1 - patient in the horizontal position on the back, finding the thickest place on the thigh, and then measuring its distance from the base of the knee-cap. At the examination of the second limb, when testing second limb, first there has to be a transfer of noted distance and then the performance of the measurement. The femoral measurement 2: the patient lies backwards, measuring $10 \mathrm{~cm}$ from the base of the knee-cap, then the realization of the circumferential measurement of the thigh. Then there is an examination on the second limb. The knee-measurement is performed on the level of the crack of the knee joint in both limbs. ${ }^{10,12,13}$

Laitinen's pain indicator questionnaire was used to qualify comprehensively pain complaints of movement system. It contains the set of four questions concerning the character of pain (intensity and frequency) and the degree of functional limitation and pharmacotherapy applied within previous seven days. Every answer was scored from 0 to 4; maximally it was possible to get 16 points. The research was performed twice, on the first and $28^{\text {th }}$ day $^{14}$. Additionally, in both groups there was introduced a poll containing the information related to the lifestyle and evaluation of effectiveness of physiotherapy (in the scale 1-10 points).

At persons from the experimental group apart from the standard- rehabilitative conduct, chosen applications of kinesiotaping have been used for four weeks. Tapes were changed after seven days. The application was put on the skin, in the form of the tape in the shape of "Y" with the lengthened base. The beginning of the tape without stretching was stuck on the level of the pelvic front bottom spike to the musculotendinous connection, then there were straps spread to surround the knee-cap and the ends were applied on the level of the tuberosity of the tibial bone, also without the stretching. The tape was extended from 15 to $50 \%$. It was applied from the proximal part to distal one - a technique of an adjunct of the quadriceps of the thigh. Tapes on the lateral and paracentrical side of the lower limb, in the shape of the letter "I", were to stimulate mechanoreceptors and proprioceptors. The knee joint was kept in the neutral position. The beginning of the application without stretching, starts below the popliteal fossa, round the calf, the centre part beginning from the tuberosity of the tibia to condyles of the femur, was stretched from 75 to $100 \%$. The application was finished without the stretching (Figure 1). ${ }^{15}$ 
All patients used kinesiotherapy. The studied persons performed isometric exercises, active in the relief, selfaided, in closed and open kinematic chains, proprioceptive and had training on the stationary cycle. The exercises were executed under the supervision of a therapist. Classes took place five times a week and every meeting lasted about three hours.

Basic statistic tools were used - the arithmetic means with standard deviations. Differences between the results of each measurement were counted by means of Wilcoxon signed-rank test. The U Mann-Whitney test was used for the estimation of differences between the groups. The minimum significance level was fixed on level $\mathrm{p} \leq 0.05$. Data was analyzed using Statistica version 10.0.

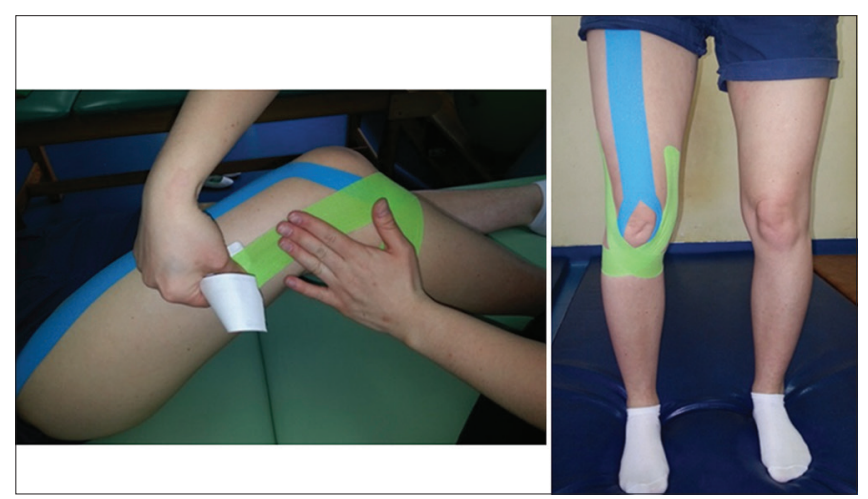

Figure 1: Application KT for quadriceps femoris with supporting proprioception

\section{RESULTS}

All patients demonstrated significant improvement in the range of the knee flexion of the injured limb as soon as the end of the first week of rehabilitation $(p<0.001)$. This tendency persisted in the following weeks until the twentyeighth day. There were no essential differences shown at patients at each measurements of the healthy limb (Table.1).

At patients of both groups were shown some characteristic differences $(p<0.001)$ between the first and the second measurement of the examination of knee extension in the damaged limb. Patients from the experimental group demonstrated imperceptibly smaller improvement (in consecutive measurements), than the patients from the control group, yet also the first day of the rehabilitation they were characterized with the lower limitation of knee extension (Table 1).

The study of the circumference of the thigh (femoral $1^{\text {st }}$ ) in the injured limb showed characteristic differences for patients of both groups (Group $1-\mathrm{p}<0.01$; Group 2 $-p<0.05)$ between the second and third measurement. Additionally, patients from the experimental group demonstrated considerable improvement $(\mathrm{p}<0.05)$ between the third and fourth measurement (Table 1).

The examination of circumference measurement of the thigh - femoral $2^{\text {nd }}$ in the damaged limb showed

\begin{tabular}{|c|c|c|c|c|c|c|c|c|}
\hline & \multicolumn{4}{|c|}{$\begin{array}{l}\text { Damaged limb } \\
\text { Measurements }\end{array}$} & \multicolumn{4}{|c|}{$\begin{array}{l}\text { Healthy limb } \\
\text { Measurements }\end{array}$} \\
\hline & 1 & 2 & 3 & 4 & 1 & 2 & 3 & 4 \\
\hline \multicolumn{9}{|c|}{ Knee flexion $\left[{ }^{\circ}\right]$} \\
\hline All & 105 & $111.7^{* \star *}$ & $118.3^{* * *}$ & $124.1^{* \star *}$ & 129.8 & 129.8 & 129.8 & 129.6 \\
\hline Group 1 & 104.5 & $112.1^{* * *}$ & $121.8^{\star * *}$ & $127.7^{\star \star *}$ & 132.7 & 132.7 & 132.7 & 132.3 \\
\hline Group 2 & 105.4 & $111.3^{* * *}$ & $115^{\star \star}$ & $120.8^{\star \star *}$ & 127.1 & 127.1 & 127.1 & 127.1 \\
\hline \multicolumn{9}{|c|}{ Knee extension $\left[{ }^{\circ}\right]$} \\
\hline All & 6.73 & $3.04^{* * *}$ & $0.43^{* * *}$ & 0.21 & 0.21 & 0.21 & 0 & 0 \\
\hline Group 1 & 6.36 & $2.27^{\star \star}$ & $0.45^{\star *}$ & 0 & 0 & 0 & 0 & 0 \\
\hline Group 2 & 7.08 & $3.75^{\star \star \star}$ & $0.41^{* * *}$ & 0.41 & 0.41 & 0.41 & 0 & 0 \\
\hline \multicolumn{9}{|c|}{ Femoral measurement $1[\mathrm{~cm}]$} \\
\hline All & 58.57 & 58.65 & $58.93^{\star \star *}$ & $59.22^{\star \star}$ & 59.8 & 59.87 & 59.91 & 59.91 \\
\hline Group 1 & 59.77 & 59.91 & $60.18^{\star *}$ & $60.55^{\star}$ & 61.05 & 61.09 & 61.14 & 61.09 \\
\hline Group 2 & 57.46 & 57.5 & $57.79^{*}$ & 58 & 58.67 & 58.75 & 58.79 & 58.83 \\
\hline \multicolumn{9}{|c|}{ Femoral measurement $2[\mathrm{~cm}]$} \\
\hline All & 46.19 & $46.54^{\star * *}$ & $46.85^{\star *}$ & $47.11^{* *}$ & 47.43 & 47.5 & 47.57 & 47.63 \\
\hline Group 1 & 47.26 & $47.77^{\star \star \star}$ & $48^{*}$ & $48.36^{\star \star}$ & 48.5 & 48.59 & 48.59 & 48.64 \\
\hline Group 2 & 45.21 & $45.42^{\star \star}$ & $45.79^{*}$ & $45.96^{*}$ & 46.46 & 46.5 & 46.63 & 46.71 \\
\hline \multicolumn{9}{|c|}{ Knee measurement $[\mathrm{cm}]$} \\
\hline All & 40.7 & $40.39^{\star * *}$ & $40.22^{\star *}$ & $39.8^{* *}$ & 39.26 & 39.26 & 39.26 & 39.3 \\
\hline Group 1 & 41.27 & $40.91^{* * *}$ & $40.68^{* *}$ & $40.14^{\star \star}$ & 39.82 & 39.82 & 39.82 & 39.82 \\
\hline Group 2 & 40.17 & $39.92^{\star *}$ & 39.79 & $39.5^{\star}$ & 38.75 & 38.75 & 38.75 & 38.83 \\
\hline
\end{tabular}


characteristic differences at persons of both groups in all measurements. However, higher significance level was noted in Group 1. The dynamics of enlarging the muscular mass of the quadriceps femoris muscle of the thigh was similar in both groups (Table 1).

At patients from the experimental group an essential reduction of the swelling in all consecutive measurements was found. The greatest difference $(p<0.001)$ was noted at the beginning of the rehabilitation, in the experimental group. Patients from the control group demonstrated significant difference between the first and the second measurement $(p<0.01)$ and the third and the fourth one $(\mathrm{p}<0.05)($ Table 1$)$.

Analysing results of the pain indicator according to Laitinen, it was shown that persons from the experimental group on the first day had been characterized with the lower intensity of pain than the patients from the control group. After twenty eight days, the intensity of pain significantly diminished at patients from both groups. Also the frequency of pain decreased. Patients from the control group used analgesics significantly more often. Differences (between the groups) deepened in the second measurement. The first test results show that the pain was greatly a reason of the limitation of activity for all studied persons. After 28 days of rehabilitation, this problem in greater degree referred to persons from Group 2. At patients from both groups' essential differences between the first and the second measurement in all four variables were demonstrated (Table 2).

Patients at who had an application of kinesiotaping considerably higher evaluated the effectiveness of physiotherapeutic treatment in all rated categories. The highest opinion was of the effectiveness of restitution and the range of motion in the injured joint (Figure 2).

\section{DISCUSSION}

Kinesiotaping is being an increasingly more often used method supplementing rehabilitation of patients with various movement system injuries. In the scientific literature, as well as in the clinical practice, the increase of interest with this method is being noted. According to its originator - Kenzo Kase, positive effects are obtained due to the mechanism of the KT tapes activity. Applied directly on skin, the tape causes delicate stimulation of layers of the epidermis, what improves the circulation of the lymph and effects on the condition of fasciae. Kase claimed that for the use of the KT method the following can be observed: the activation of the analgesic system,

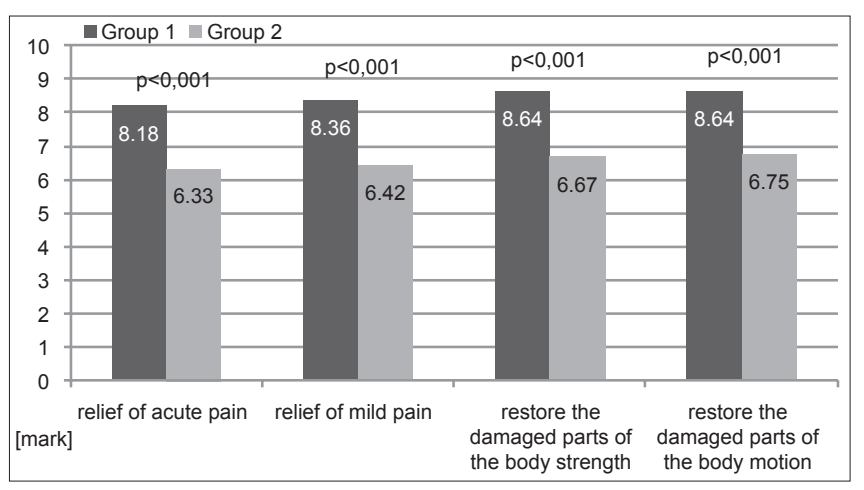

Figure 2: Assessment of physiotherapeutic treatments

\begin{tabular}{|c|c|c|c|}
\hline & 1. day & 28. day & Difference [p] \\
\hline \multicolumn{4}{|l|}{ Group 1} \\
\hline Intensity of pain & 1.755 & 0.727 & $p<0.01$ \\
\hline Frequency of pain & 1.636 & 0.636 & $p<0.01$ \\
\hline Use of analgesics & 1.364 & 0.091 & $p<0.001$ \\
\hline Decreased activity & 1.727 & 0.273 & $p<0.001$ \\
\hline \multicolumn{4}{|l|}{ Group 2} \\
\hline Intensity of pain & $2.250^{*}$ & 1.000 & $p<0.001$ \\
\hline Frequency of pain & 2.167 & $1.167^{*}$ & $p<0.01$ \\
\hline Use of analgesics & 1.750 & $0.667^{*}$ & $p<0.001$ \\
\hline Decreased activity & 1.833 & 0.833 & $p<0.01$ \\
\hline
\end{tabular}

reduction of swellings and subcutaneous haemorrhages, regulation of the muscular tension or the correction of the irregular position of the articular surfaces. ${ }^{15,16}$

Scientific literature offers results of various studies, which prove the positive features of the kinesiotaping method in the treatment and prophylaxis of body injuries. ${ }^{17-20}$

E.g. the profitable influence of the KT method at patients with the Scheuermann's disease was shown. The physiotherapy of these persons was based on the use of the combination of the kinesiotaping method and PNF. ${ }^{21}$ Also KT usefulness was demonstrated as an adjunct to the rehabilitation of patients after the reconstruction of the anterior sacral ligament. Findings showed the diminution of the surgical swelling, and also of the need of pharmacological resources -the analgesic effect was obtained..$^{22}$ Kinesiotaping was successfully applied at persons struggling with the chronic pain, whether patients with neurological diseases or of rheumatologic ones. Most often the analgesic and anti-oedematous properties of elastic tapes were emphasized. ${ }^{23-27}$ Similar conclusions were reached by this own study. Faster swelling reduction and rarer usage of analgesic medicines (the pain indicator according to Laitinen) were found among patients using KT. 
Kinesiotaping is a method which can cause the diminution or enlargement of tension, liquidation of pain and lymphedemas, it can support joints, and also it can make the correction of various structures possible. In the literature, however, there is no information on the application of this method as an element of rehabilitation adjunction at patients with injured menisci.

Many authors emphasize that every dysarthrosis demands individual improving, for the pain increase, damage degree, time wherein the rehabilitation began, only the aim of therapy is always the same: achievement of satisfying range of motion and function as well as reduction of pain in as short time as possible. ${ }^{21,22}$

After four-week long rehabilitation, at all persons (studied for the present research), the range of motion of injured limb reached close values to the value of an unimpaired limb. Patients from the experimental group reached more quickly the improvement of flexibility of the knee joint.

The results of this study show that the essential increase of the mass and muscular power can be obtained with isometric exercises, active resistance exercises together with the KT method. However, the period of four weeks proved to be inadequate for the entire restoration of the muscular mass from before the trauma. It is recommended to continue exercises and to extend the period of rehabilitation.

Obtained results may not fully reflect the real influence of the applied method. Not very numerous groups were the result of the intended selection of patients according to their age, the kind of injury and the lack of other illnesses. The measurements might not be accurate, though they were taken by one researcher. In the later phase, not all patients performed shown exercises exactly; it resulted from the fast and visible improvement and the lack of need for honest exercise. The study of the effectiveness of the usage of the kinesiotaping method should be continued for the purpose of more exact examining of the influence of elastic tapes on progress of rehabilitation following the arthroscopic intervention. It seems legitimate to research other kinds of applications, giving better effects after knee injuries. It is proper also to try to combine this therapeutic method with other one, for the purpose of as fast return of the patient to the physical and professional activities.

\section{CONCLUSIONS}

1. The restitution of the motion range in the knee joint and mass of the quadriceps was similar in both groups, though the kinesiotaping use accelerated the process of rehabilitation in this range. The used application (strengthening the power and helping proprioception) therefore, fulfilled its part.

2. At patients who had tapes applied, faster reduction of oedema in the knee joint was observed. This can show the improvement of circulation in the injured limb, which is one of the main advantages of the kinesiotaping therapy.

3. Similar reduction in the pain intensity was observed in all patients. However, after 28 days of rehabilitation, pain significantly less often forced patients from the experimental group to use analgesic medicines. This means that they returned to everyday duties faster and more efficiently. Kinesiotaping can be used in the therapy of pain (also of other origins).

4. Findings can become a basis for the randomized prospective research with the participation of more numerous experimental groups.

\section{REFERENCES}

1. Bahr R. Injury prevention. [in:] Reeser JC, Bahr R. (eds.) Volleyball: Handbook of Sports Medicine and Science, Blackwell, Malden 2003, 94-106.

2. Cumps E, Verhagen $E$ and Meeusen R. Prospective epidemiological study of basketball injuries during one competitive season: Ankle sprains and overuse knee injuries. Journal of Sports Science and Medicine. 2007, (6), 204-211.

3. Girardi P, Braggion M, Sacco G, De Giorgi F and Corra S. Factors affecting injury severity among recreational skiers and snowboarders: an epidemiology study, Knee Surgery, Sports Traumatology, Arthroscopy 2010; 18: 1804-1809.

4. Goulet C, Hagel BE, Hamel D and Legare G. Self-reported skill level and injury severity in skiers and snowboarders, Journal of Science and Medicine in Sport 2010; 13: 39-41.

5. Li J, Lu L, Zhu W, Shi D, Zhan K and Wang Y. Arthroscopic characteristics of meniscal injuries in osteoarthritic knees. Acta Orthop Traumatol Turc 2014; 48(3):276-282.

6. Chowdhury AZ, Sakeb N, Arifeen MN, Selimullah AM, Joarder Al and Salek AM. Comparison between Arthroscopic Partial and Total Meniscectomy of Medial Meniscus in Non-Professional Athletes. Mymensingh Med J 2014; 23(2): 305-314.

7. Michaelidis $M$ and Koumantakis GA. Effects of knee injury primary prevention programs on anterior cruciate ligament injury rates in female athletes in different sports: A systematic review. Phys Ther Sport 2013; S1466-853X(13)00112-0. doi: 10.1016/j. ptsp.2013.12.002. [Epub ahead of print]

8. Wilson SM, Mehta N, Do HT, Ghomrawi H, Lyman S and Marx RG. Epidemiology of Multiligament Knee Reconstruction. Clin Orthop Relat Res 2014 Apr 29. [Epub ahead of print]

9. Kubiak $G$ and Fabiś J. Clinical results of meniscus repair. Ortop Traumatol Rehabil, 2010; 12(1): 28-40.

10. Fibiger W, Kukiełka R, Jasiak-Tyrkalska B and Frańczuk B. Rehabilitation after damage to the anterior cruciate ligament for persons actively participating in sport. Ortop Traumatol Rehabil 2004; 6(4): 461-466.

11. Gaweł J, Fibiger W, Starowicz A and Szwarczyk W. Early assessment of knee function and quality of life in patients after total knee replacement. Ortop Traumatol Rehabil 2010; 12(4): 329-334. 
12. Czamara A. Functional benchmarks of musculoskeletal fitness following knee joint anterior cruciate ligament reconstruction. Polish Journal Physiotherapy 2010;10(4): 247-262.

13. Kiwerski J. Rehabilitacja Medyczna. Warszawa: PZWL; 2007.

14. Korzeniowska K and Szałek E. The pain. Farm Wspol 2010; 3:9-14.

15. Kase K. Ilustrated Kinesio Taping. Ken'l - Kai Information, Tokyo 2002.

16. Kalron A and Bar-Sela S. A systematic review of the effectiveness of Kinesio Taping ${ }^{\circledR}$ - Fact or fashion?, European Journal of Physical and Rehabilitation Medicine (Europa Medicophysica) 2013; 49(5): 699-709.

17. Białoszewski D, Woźniak W and Żarek S. Clinical efficacy of Kinesiology Taping in Reducing Edema of the Lower Limbs in Patients Treated with the llizarov Method. Preliminary Report, Ortop Traumatol Rehabil 2009; 1(6): 46-54.

18. Merino-Marba R, Mayorga-Vega $D$ and Fernandez-Rodriguez E. Effect of Kinesio Tape Application on Calf Pain and Ankle Range of Motion in Duathletes. Journal of Human Kinetics 2013; 37: 129-135.

19. Chang HY, Chou KY, Lin JJ, Lin CF and Wang CH, Immediate effect of forearm Kinesio taping on maximal grip strength and force sense in healthy collegiate athletes. Physical Therapy in Sport 2010; 11(4): 122-127.

20. Lumbroso D, Ziv E, Vered E and Kalichman L. The effect of kinesio tape application on hamstring and gastrocnemius muscles in healthy young adults, Journal of Bodywork and Movement Therapies 2014; 18: 130-138.
21. Grudzien M. Potential applications of the PNF method and kinesiotaping in the treatment of juvenile thoracic kyphosis, Acta Bio-Optica et Informatica Medica 2009; 15(2): 106-107.

22. Boguszewski D, Tomaszewska I, Adamczyk JG and Białoszewski D. Evaluation of effectiveness of Kinesiology Taping as an adjunct to rehabilitation following anterior cruciate ligament reconstruction. Preliminary report. Ortop Traumatol Rehabil 2013; 15(5): 469-478.

23. Castro-Sanchez A, Lara-Palomo I, Mataran-Penarrocha G, Fernandez-Sanchez M, Sanchez-Labraca N and ArroyoMorales M. Kinesio Taping reduces disability and pain slightly in non-specific low back pain: a randomized trial. J Physiother 2012; 58(2): 89-95.

24. Kuru T, Yalıman A and Dereli EE. Comparison of efficiency of Kinesio ${ }^{\circledR}$ taping and electrical stimulation in patients with patellofemoral pain syndrome. Acta Orthop Traumatol Turc 2012; 46(5): 385-392.

25. Jaraczewska $E$ and Long C. Kinesio Taping In stroke: improving functional use of the upper extremity In hemiplegia, Topics in Stroke Rehabilitation 2006; 13(3):31-42.

26. Karatas N, Bicici S, Baltaci $G$ and Caner $H$. The effect of Kinesiotape application on functional performance in surgeons who have musculo-skeletal pain after performing surgery. Turk Neurosurg 2012; 22(1): 83-89.

27. Şimşek T, Turkucuoglu B, Cokal N, Ustanbaş G and Şimşek I. The effects of Kinesiotaping on sitting posture, functional independence and gross motor function in children with cerebral palsy. Disabil Rehabil; 2011: 33(21-22): 2058-2063.

Authors Contribution:

DB - Concept and design, analysis and interpretation, manuscript preparation, revision of the manuscript and literature search; IT - Data collection, preparation of manuscript; JGA - Manuscript preparation, revision of the manuscript and literature search DBi - Revision of the manuscript and literature search.

Source of Support: Nil, Conflict of Interest: None declared. 